\title{
Frequency of Work Related Musculoskeletal Disorders among Nurses Working in Hospitals of Lahore
}

\author{
Faizan Asghar ${ }^{1}$, Sarah Ehsan ${ }^{2}$, Hafiz Sheraz Arshad ${ }^{3}$ \\ ${ }^{1}$ Physical Therapist, Azra Naheed Medical College, Department of Physical Therapy, Main Raiwind Road, Lahore \\ ${ }^{2}$ Senior lecturer, Azra Naheed Medical College, Department of Physical Therapy, Main Raiwind Road, Lahore \\ ${ }^{3}$ Head of Department/Assistant professor, Azra Naheed Medical College, Department of Physical Therapy, Main Raiwind Road, Lahore
}

\begin{abstract}
Nurses regularly perform activities that are repetitive and include direct interaction with the patient. Such activities are the major cause of the work related musculoskeletal problems.A descriptive study was conducted among nurses in different hospitals of Lahore. Convenient sampling technique was used. Nordic questionnaire was distributed among 195 respondents to collect data. Data was analyzed through SPSS, Mean and standard deviation was calculated for quantitative variables while frequencies and percentages were calculated for categorical variables.During last 12 months pain was experienced most frequently in low back (49.7\%) followed by shoulder (35.4\%) by the nurses. The least frequently involved region of pain was elbow (15.9\%). Most of the participant respondents responded difficulty in performing any activities in last 12 months due to symptoms in lower back (45.6\%), followed by neck (29.2\%). Our study revealed that nurses while performing their activities face different types of musculoskeletal disorders due to their nature of profession. Most commonly involved regions were lumbo sacral region (low back pain), shoulder and neck.
\end{abstract}

Keywords: Nurses, Low back pain, musculoskeletal disorders, Nordic questionnaire, Pain

\section{Introduction}

\subsection{Overview}

Musculoskeletal problems are also correlated as work related musculoskeletal problem which happens after a work associated event. Work related problems are the main cause of work disability. Most common problems are low back pain, tenderness of the calf muscle pain in the knee and ankle as well in upper limbs and shoulder.[1]

Nurses regularly perform activities that are repetitive severe, including direct interaction with the patient. Such activities are the major cause of the work relevant problems. Nurses are not well known about these problems. The purpose of this study is to check the incidence of musculoskeletal problems between nurses within one year.[2]

Nurses have to face various risks at their job in which most common are biological risks ergonomic problems and work associated stress. There is some problem, including work related are present in all nurses. The nursing profession is a high risk profession for musculoskeletal disorders. The reason of the study is to check the frequency of musculoskeletal disorders between nurses working in a hospital.[3]

Nurses in Korea experience back pain in $72 \%$ of cases musculoskeletal symptoms 7.2 reported in nurses who perform manual treatment of the patient. The frequency of back problems was $36 \%$ in the Netherlands and $63 \%$ in Cape Town. Physical variables which were the main reason of back pain in nurses lifting $65 \%$ working with abnormal posture $47 \%$ stooping $34 \%$ and poor posture in the ward
$53 \%$. Frequency of back pain in the intensive care unit was $84 \%$ and $64 \%$ of those nurses who are working in other wards this study has been done on 4077 nurses.[4]

Previous study has been done in university of Ilorin teaching hospital in Nigeria

Previous study was done within 454 health care workers included nurses and their assistants in Iran's general hospital.[5]

Davis and Kotowski et al., in 2015 designed a research on the occurrence of musculoskeletal problems in nurses. Work related musculoskeletal complaints have been investigated all over the world in professional nurses largely focused on lower back pain. The study showed us that nowadays new changes occurred in responsibilities of health care professionals for example weight bearing, mobility and home sickness care also provided by nurses so that shoulder and upper limb may largely affect.[6]

\subsection{Objective}

To find out the frequency of musculoskeletal disorders among nurses working in hospitals of Lahore

\subsection{Rationale}

This study will be helpful in identifying the musculoskeletal disorders among nurses and would thus be helpful in improving quality of life. 


\section{International Journal of Science and Research (IJSR) \\ ISSN (Online): 2319-7064}

Index Copernicus Value (2013): 6.14 | Impact Factor (2015): 6.391

\subsection{Operational Definitions}

\subsubsection{Nordic Questionnaire}

This is a self-administered questionnaire and for nonidentical answers and its validity and reliability is $0.74-$ $0.80 \%$. Sensitivity of nordic style questionnaires is 82.3 $100 \%$. Specificity varies according to the severity of symptoms (51.1-82.4\%).[7]

\subsection{Materials and Methods}

\subsubsection{Study Design}

This study was a descriptive, cross-sectional study

\subsubsection{Setting}

Data was collected from different hospital of Lahore.

\subsubsection{Study Population}

The study population was female Nurses

\subsubsection{Duration of study}

This study was completed in 3 months.

1.5.5. Sample size

A Sample of 195 nurses has been taken from a population of 20000 estimated.

\subsubsection{Sampling technique}

Convenient sampling

\subsubsection{Eligibility}

\subsubsection{Inclusion criteria}

- Data collected from nurses working in different hospitals of Lahore with age group of 18 to 56 years.

- Working as a full time nurse with work time not less than 8 hours a day and at least one year of work experience.

\subsubsection{Exclusion criteria}

- Nurses who were experiencing any chronic disease or recently diagnosed with a disease i.e inflammatory, psychological, fibromyalgia.

- Those not willing to participate.

\subsubsection{Data collection}

Data was collected from 195 nurses by using convenient sampling technique from the hospitals of Lahore; musculoskeletal disorders were analyzed by the use of Nordic questionnaire, after taking an informed consent. A questionnaire was distributed among nurses, including a first part about demographic characteristics like age, marital status, parity, height, weight, shifting at work and their experience; the second part consisted of standardized Nordic questionnaire that asked about the pain experienced in different regions of body.

\subsubsection{Ethical consideration}

The researcher followed all the ethics of the medical field.

\subsubsection{Statistical procedure}

All data was entered and analyzed through SPSS software Mean \pm standard deviation was calculated for quantitative variable while frequencies and percentages were used for qualitative variables.

\section{Results}

The mean age of nurses in years was $24.89(\mathrm{SD}=9.04)$, with a minimum of 18 years and maximum age of 56 years. Out of 195 nurses $75.4 \%$ were single.

Table 1: Number of Patients dealt per shift

\begin{tabular}{|c|c|c|}
\hline & Frequency $(n=195)$ & Percent $(\%)$ \\
\hline $30-50$ & 75 & 38.5 \\
\hline $51-70$ & 96 & 49.2 \\
\hline$>70$ & 24 & 12.3 \\
\hline
\end{tabular}

Majority of the Nurses ( $n=96,49.2 \%)$ reported that they dealt with 51-70 patients per shift. More than 70 patients per shift were being dealt by $12.3 \%$ nurses.

Table 2: Frequency of Job tenure

\begin{tabular}{|c|c|c|}
\hline & Frequency & Percentage \\
\hline 1-2 years & 56 & 28.7 \\
\hline 3-4 years & 90 & 46.2 \\
\hline 5 years and greater & 49 & 25.2 \\
\hline
\end{tabular}

Most of the nurses ( $n=90,46.2 \%)$ had 3-4 years of job tenure.

Table 3: Region wise frequencies of Pain during last 12 months

\begin{tabular}{|c|c|c|}
\hline \multirow{2}{*}{ Region } & \multicolumn{2}{|c|}{ Any symptoms in last 12 months (N=195) } \\
\cline { 2 - 3 } & Yes & No \\
\hline Neck & $63(32.3 \%)$ & $131(67.2 \%)$ \\
\hline Shoulder & $69(35.4 \%)$ & $125(64.1 \%)$ \\
\hline Upper back & $44(22.6 \%)$ & $151(77.4 \%)$ \\
\hline Elbows & $31(15.9 \%)$ & $164(81.4 \%)$ \\
\hline Wrist/hands & $47(24.1 \%)$ & $148(75.9 \%)$ \\
\hline Lower back & $97(49.7 \%)$ & $98(50.3 \%)$ \\
\hline Hip/thigh & $56(28.7 \%)$ & $139(71.3 \%)$ \\
\hline Knees & $62(31.8 \%)$ & $133(68.2 \%)$ \\
\hline Ankle/foot & $65(33.3 \%)$ & $130(66.7 \%)$ \\
\hline
\end{tabular}

During last 12 months pain was experienced most frequently in low back $(n=97)$ followed by shoulder $(n=69)$ by the nurses. The least frequently involved region of pain was elbow $(n=31)$.

Table 4: Descriptive statistics for difficulty in performing any activities, due to symptoms in last 12 months

\begin{tabular}{|c|c|c|}
\hline \multirow{2}{*}{ Region } & Difficulty in activities in last 12 months (N=195) \\
\cline { 2 - 3 } & Yes & No \\
\hline Neck & $57(29.2) \%$ & $138(70.8) \%$ \\
\hline Shoulder & $54(27.7) \%$ & $141(72.3) \%$ \\
\hline Upper back & $34(17.4) \%$ & $161(82.8) \%$ \\
\hline Elbows & $24(12.3) \%$ & $171(87.7) \%$ \\
\hline Wrist/hands & $45(23.1) \%$ & $150(76.9) \%$ \\
\hline Lower back & $89(45.6) \%$ & $106(54.4) \%$ \\
\hline Hip/thigh & $45(23.1) \%$ & $149(76.4) \%$ \\
\hline Knees & $54(27.4) \%$ & $140(71.8) \%$ \\
\hline Ankle/foot & $49(25.1) \%$ & $146(74.9) \%$ \\
\hline
\end{tabular}

Most of the participant respondents responded difficulty in performing any activities in last 12 months due to symptoms in lower back $(n=89)$, followed by neck $(n=57)$ 


\section{International Journal of Science and Research (IJSR) \\ ISSN (Online): 2319-7064 \\ Index Copernicus Value (2013): 6.14 | Impact Factor (2015): 6.391}

Table 5: Descriptive statistics for "have you ever seen a physician for this condition, in last 12 months?"

\begin{tabular}{|c|c|c|}
\hline \multirow{2}{*}{ Region } & \multicolumn{2}{|c|}{$\begin{array}{c}\text { Seen A physician for this condition, in last 12 } \\
\text { months(N=195) }\end{array}$} \\
\cline { 2 - 3 } & Yes & No \\
\hline Neck & $51(26.2) \%$ & $143(73.3) \%$ \\
\hline Shoulder & $35(17.9) \%$ & $159(81.5) \%$ \\
\hline Upper back & $30(15.4) \%$ & $165(84.6) \%$ \\
\hline Elbows & $18(9.2) \%$ & $177(90.8) \%$ \\
\hline Wrist/hands & $30(15.4) \%$ & $165(84.6) \%$ \\
\hline Lower back & $71(36.4) \%$ & $124(63.6) \%$ \\
\hline Hip/thigh & $36(18.5) \%$ & $159(81.5) \%$ \\
\hline Knees & $43(22.1) \%$ & $152(77.9) \%$ \\
\hline Ankle/foot & $28(14.4) \%$ & $167(85.6) \%$ \\
\hline
\end{tabular}

The most frequent region for which the respondents had to see a physician was lower back $(n=71)$ followed by neck $(\mathrm{n}=51)$.

Table 6: Descriptive statistics for "any trouble during last 7 days"

\begin{tabular}{|c|c|c|}
\hline \multirow{2}{*}{ Region } & \multicolumn{2}{|c|}{ Any trouble during last seven days (N=195) } \\
\cline { 2 - 3 } & Yes & No \\
\hline Neck & $62(31.8) \%$ & $133(68.2) \%$ \\
\hline Shoulder & $64(32.8) \%$ & $131(67.2) \%$ \\
\hline Upper back & $37(19.0) \%$ & $158(81.0) \%$ \\
\hline Elbows & $32(16.4) \%$ & $162(83.1) \%$ \\
\hline Wrist/hands & $47(24.1) \%$ & $148(75.9) \%$ \\
\hline Lower back & $85(43.6) \%$ & $110(56.4) \%$ \\
\hline Hip/thigh & $56(28.7) \%$ & $139(71.3) \%$ \\
\hline Knees & $65(33.3) \%$ & $130(66.7) \%$ \\
\hline Ankle/Foot & $50(25.6) \%$ & $145(74.4) \%$ \\
\hline
\end{tabular}

Most frequent region for "any trouble during last seven days" was lower back $(n=85)$ followed by knees $(n=65)$. The least frequent region reported was elbow $(n=32)$.

\section{Discussion}

The results of currents study have shown that during last 12 months pain was experienced most frequently in low back, shoulder and neck by the nurses. The least frequently involved region of pain was elbow.

The results showed that frequency of musculoskeletal disorders was high among the nurses. Most of the nurses had to deal with 50-70 patients per shift. Most of the nurses had 3-4 years of experience.

Nurses perform activities which are necessary that predispose them to various musculoskeletal problems. [1] It has been reported that due to the nature of work and working in bad posture consistently nurses are predisposed to musculoskeletal.

In current study in last 12 months most frequent problem found in nurses was low back pain.

It has been that three main factors that cause musculoskeletal problems include repetitive movement heavy work load and working in awkward postures. Seventy five percent $(75 \%)$ of low back pain problems include tears twists and strains and about (70\%) occur due lifting heavy weights pushing and shifting the patients etc. [8]
Shoulder and back problems have been found prevalent among nurses in a previously conducted study. [9]

The results of our study are consistent with the results of previous study conducted on self- reported musculoskeletal problems in nurses. Neck, shoulder and back were frequently reported areas of pain and showed a significant association with work demands.[10]

Nurses regularly work in different postures and different awkward postures adopted by nurses which cause musculoskeletal problems. Current study is in agreement with Frost et al, who have suggested that nurses between ages of 20-50 have evidence of musculoskeletal problems. And the risk factors for these musculoskeletal problems include repetitive task and lifting heavy loads. And their most common musculoskeletal problem included back pain. [11]

\section{Conclusion}

This study concludes that nurses while performing their activities face different types of musculoskeletal disorders due to their nature of profession. Most commonly involved region was lumbo sacral region (low back pain) and neck pain. Further research on ergonomic work posture analysis of nurses is highly recommended.

\section{References}

[1] GOSWAMI, S., HALDAR, P. \& SAHU, S. 2013. An ergonomic study of postural stress of nurses working in orthopedic wards. International Journal of Occupational Safety and Health, 3, 26-31.

[2] NKHATA, L. A., ESTERHUIZEN, T. M., SIZIYA, S., PHIRI, P. D., MUNALULA-NKANDU, E. \& SHULA, H. 2015. The Prevalence and Perceived Contributing Factors for Work-Related Musculoskeletal Disorders Among Nurses at the University Teaching Hospital in Lusaka, Zambia. Science, 3, 508-513.

[3] MEHRDAD, R. \& MORSHEDIZADEH, M. 2012. Musculoskeletal disorders and ergonomic hazards among Iranian physicians. Archives of Iranian medicine, 15,370 .

[4] HINMIKAIYE, C. \& BAMISHAIYE, E. 2012. The incidence of low back pain among theatre nurses: a case study of university of ilorine and obafemi Awolowo university teaching hospital. International Journal of Nursing science, 2, 23-28.

[5] ATTARCHI, M., RAEISI, S., NAMVAR, M. \& GOLABADI, M. 2014. Association between shift working and musculoskeletal symptoms among nursing personnel. Iranian journal of nursing and midwifery research, 19, 309-14.

[6] DAVIS, K. G. \& KOTOWSKI, S. E. 2015. Prevalence of Musculoskeletal Disorders for Nurses in Hospitals, Long-Term Care Facilities, and Home Health Care A Comprehensive Review. Human Factors: The Journal of the Human Factors and Ergonomics Society, 0018720815581933.

[7] Descatha A, Roquelaure Y, Chastang J-F, Evanoff B, Melchior M, Mariot C, et al. Validity of Nordic-style questionnaires in the surveillance of upper-limb work- 


\section{International Journal of Science and Research (IJSR) \\ ISSN (Online): 2319-7064}

Index Copernicus Value (2013): 6.14 | Impact Factor (2015): 6.391

related musculoskeletal disorders. Scandinavian journal of work, environment \& health. 2007;33(1):58.

[8] SILVERSTEIN, B. A., FINE, L. J. \& ARMSTRONG, T. J. 1987. Occupational factors and carpal tunnel syndrome. American journal of industrial medicine, 11, 343-358.

[9] TRINKOFF, A. M., LIPSCOMB, J. A., GEIGER-BROWN， J. \& BRADY， B. 2002. Musculoskeletal problems of the neck, shoulder, and back and functional consequences in nurses. American journal of industrial medicine, 41, 170-178.

[10] TRINKOFF, A. M., LIPSCOMB, J. A., GEIGERBROWN, J., STORR, C. L. \& BRADY, B. A. 2003. Perceived physical demands and reported musculoskeletal problems in registered nurses. American Journal of Preventive Medicine, 24, 270-275.

[11] FROST, P., BONDE, J. P. E., MIKKELSEN, S., ANDERSEN, J. H., FALLENTIN, N., KAERGAARD, A. \& THOMSEN, J. F. 2002. Risk of shoulder tendinitis in relation to shoulder loads in monotonous repetitive work. American journal of industrial medicine, 41, 1118.

\section{Author Profile}

FaizanAsghar is Physical Therapist, Azra Naheed Medical College, Department of Physical Therapy, Main Raiwind Road, Lahore

Sarah Ehsan is Senior Lecturer, Azra Naheed Medical College, Department of Physical Therapy, Main Raiwind Road, Lahore

Hafiz SherazArshad is Head of Department/Assistant Professor, Azra Naheed Medical College, Department of Physical Therapy, Main Raiwind Road, Lahore 